THE WABASH CENTER

JOURNAL on TEACHING

\title{
Locating US Theological Education in a Global Context: Conversations with American Higher Education
}

\author{
Hendrik R. Pieterse, editor \\ Eugene, OR: Pickwick Publications, 2020 (xvii + 180 pages, ISBN978-1-5326-1886-4, \\ $\$ 25.00)$
}

\author{
Reviewed By \\ Daniel D. Scott \\ Tyndale University
}

\begin{abstract}
The speed with which American institutions of higher learning adapted to online delivery of classes during the COVID-19 pandemic suggests US theological education could continue to adjust to global demands and could do so quickly. Adaptation to the globalization of higher education has until now been slow within US theological education. The pace could quicken and this book could help.
\end{abstract}

In the introduction, Hendrik R. Pieterse, the editor of the volume, lays out the background of this conversation within the ATS and poses the question: "With the ecology of global theological education growing increasingly salient ... how do US theological institutions 'locate' themselves amid these changes so as to be both responsible participants and creative shapers within it?" (xii). The answer, "locating," both as "locus" and "role," becomes the framing theme of the book.

The chapters by Hendrick Pieterse ("Internationalizing Theological Education? Musings on a Neglected Concept"); Namsoon Kang ("Global Politics of Knowledge and US Theological Education: From Globalization to Planetarization"); Brent Waters ("Globalization and Global Theological Education: Learning to Navigate the World of Creative Destruction"); E. Byron Anderson ("Church Affiliation and Higher Education in a Secularizing World: Insights and Questions for Theological Education"); and Lester Ruiz and David Esterline (“From 'Globalization' to 'Global Awareness and Engagement': Perspectives, Challenges, Futures") relate to "locating as place" and are concerned with how US theological education fits into the context of global theological education.

The chapters listed above by Pieterse, Ruiz and Esterline, and Rivera, along with those by K. K. Yeo (“'Made in the USA': A Chinese Perspective on US Theological Education in the Light of the Chinese Context"), and Margaret Eletta Guider ("The Globalization of Theological Education: A Roman Catholic Perspective") consider the idea of "locating as role" or what roles US theological institutions play in terms of global theological education.

As US theological institutions give consideration to both their place and their role in the global context, this collection of essays provides an excellent overview of the issues and provides some suggested courses of action and solutions. As a result, it should be required reading for faculty book clubs, academic planning committees, faculty senates, and cabinets. The issues raised are important to consider.

Institutions of higher learning are considering their global context in the development of their strategic plans more and more. This takes the form of branch campuses, joint degree programs, academic centers, online learning, and so forth. Witness the growth, for example, of institutional partnerships on various continents to offer MBA and law programs. Seminaries, faculties of religion, and other forms of US theological education must adapt to the trends of globalization and give consideration to their place and role in this. As is becoming increasingly evident, the "world is flat," (to borrow the catchy title of Thomas Friedman's 2005 international best seller from fifteen years ago). US theological education must recognize this fact and adjust its stance accordingly. This volume could, and should be, used as a primer. 